\title{
O terreiro eletrônico e a cidade: o olhar do mestre antropófago
}

Entrevista com José Celso Martinez Correa realizada por Marcos Bulhões Martins.

No mês em que completou setenta e cinco anos de vida, em plena atividade criativa, preparando a segunda temporada do espetáculo "Macumba Antropófoga”, o diretor e dramaturgo Zé Celso Martinez Correa, nos ofereceu um depoimento que sintetiza sua visão sobre a trajetória artística do Teatro Oficina, grupo reconhecido pela crítica como um dos mais significativos da nossa história1. Nos cinquenta e quatro anos de existência do grupo, foram desenvolvidas experimentações intensas de diferentes possibilidades do fazer teatral: a representação realista defendida por Stanislávski ("Pequenos Burgueses", de Gorki), o estudo da abordagem épico-dialética, ("Andorra", de Max Frisch, e "Galileu Galilei" de Brecht), até a concretização de uma cena antropofágica, centrada na tradição da comédia musical popular e na apropriação dos modelos estéticos estrangeiros, a partir do confronto com as obras de Oswald de Andrade e com o movimento tropicalista nas artes, que resultou na montagem de "Rei da Vela", marco da encenação moderna na década de 60. O encontro dos escritos de Artaud com as diversas modalidades da arte da performance foram a base do rompimento com o formato de espetáculo e da relação convencional ente a cena e o público, desenvolvidas pelo diretor no coro de "Roda Viva" e radicalizadas em "Gracias Señor", que gerou polêmicas nos anos 70. Após o exílio em Portugal e Moçambique, destacam-se as ações rituais e os happenings feitos nos anos 80, tais como, "Ensaio para o Carnaval do Povo". Em 1993, com a inauguração do novo espaço do "terreiro eletrônico", a retomada do enfrentamento dos textos clássicos foi marcada pelas montagens de "Ham-let" e "Bacantes". Ao longo dos anos 2000, Zé Celso vem desenvolvendo, uma abordagem própria de dramaturgia cênica, que mescla música, recitação poética, dança, performance, teatro épico, jogo popular, festa e carnaval que ele denomina

\footnotetext{
1 Baseamo-nos em autores como Sábato Magaldi, Ruggero Jacobbi, lam Michalviski, Décio Almeida Prado, David Jorge, Armando Sérgio, Mauro Meiches, Silvia Fernandes, Tânia Brandão, Sebastião Milaré, José da Costa, Silvana Garcia, Luís Fernando Ramos, dentre outros.
} 
"tragédiacomediorgya", revelada em espetáculos como "Os Sertões" e "Os Bandidos". Nesta primeira parte da entrevista, Zé Celso comenta esse percurso histórico, fala de sua relação com a cidade de São Paulo e reafirma com entusiasmo o projeto do Teatro de Estádio, que sonha construir no bairro do Bixiga.

\section{Para você, qual é a relação do seu trabalho com a cidade?}

É a relação de todos os Teatros que se enraízam e se antenam no espaço Urbano, Florestal, Rural ou Marítimo, numa relação de Amor que leva à ProCriacão.

OTEAT(r)O É UM POVOADOR DA PRESENÇA HUMANA ERÓTICA DA CIDADE.

Diferentemente da Catástrofe atual do "Crack", a Droga, fenômeno novo na história humana, que devasta bairros, cidades, os "Craques" de teatro são elementos aglutinadores do gozo da Orgya Humana.

\section{HISTÓRIA}

O Bairro do BIXIGA, pertenceu em toda sua extensão, chegando até o alto da atual Avenida Paulista, a uma escrava chamada "LIBERTAS" .

No Fim da Abolição da Escravidão, Ela, herdou de seus antigos Senhores, os Títulos de Propriedade desta Terra Incógnita.

Chegaram Emigrantes de todas as partes do Mundo, vindos das lavouras de Café para a Cidade que se erguia.

As Terras de LIBERTAS foram sendo progressivamente griladas por emigrantes, sobretudo italianos.

Hoje, os Negros criaram a Campeã das Escolas de Samba da Cidade, a famosa VAI-VAI. Mas, a maioria da população afro-brasileira foi tendo que viver nos "Cortiços", “Cabeças de Porco", favelas entranhadas nos subterrâneos do Bairro do BIXIGA. O Oficina vem de uma construção mestiça: com paredes de Ex-Senzalas, misturadas a "Arcos Romanos", preservados até hoje pela Arquitetura do "Arquiteto" Lina Bardi que chama seu trabalho Arquitetônico de "ARQUEOLOGIA URBANA"

Depois do fim da II Guerra Mundial, um Grande Empresário do Aço italiano: Franco Zampari, criou em escala Industrial "o Teatro Brasileiro de Comédia" e a "Cia Cinematográfica Vera Cruz:" Importou toda uma geração de brilhantes artistas Europeus e Norte Americanos do pós-Guerra que modernizou o Teatro e o Cinema Brasileiro, penetrando no bairro periférico da Capital do Capital do Brasil, São Paulo: no Bairro do BIXIGA. O TBC criou um bar dos artistas internacionais: o "Nick Bar" (nome de uma peça de Saroyan) que inspirou a florada de CANTINAS ITALIANAS até os anos 
60 do século passado. O BIXIGA tornou-se assim o Coração Cosmopolíta e Popular da Cidade de SamPã. O TBC gerou muitos outros Teat(r)os de Grandes Cias de repertório em torno de Companhias lideradas por Divas como Cacilda Becker, Maria della Costa, Nydia Licia etc.... Estas Cias. trabalhavam em seu Corpo de Atuação, sobretudo na área Técnica, com o moradores do Bairro.

O TEAT(r)O OFICINA foi gerado por jovens estudantes brasileiros, tendo à frente nomes como Eugenio Kusnet, este vindo do TBC, mas antes de um trabalho na Ópera Russa com Stanislávski, Kusnte criou um Studio no Oficina para atores de todas as Cias. Madame Morineau, vinda da Cia. de Louis Jouvet, refugiado da Ocupação da França pelos Nazistas, nos trouxe os primeiros passos em direção a Artaud. Nós começamos criando uma linha que numa $1^{\underline{a}}$ fase devorou nos nossos corpos de jovens pequenos burgueses dos anos 50-60: o Método Stanislávski e do Actor's Studim, pra suicidarmos nossas couraças emocionais de classe e auto-penetrando nossas energias, acumulá-las para estilhaçar o contorno do Corpo Pequeno Burguês, virando o Corpo Livre Revolucionário dos Anos 60.

Parte de nossa geração se entregou ao Desbunde nas Artes Revolucionárias, e outra à Luta Armada contra a Ditadura. Construímos 3 Teatros no mesmo lugar, sempre tivemos a sorte de trabalhar com Arquitetos, que nos fizeram perceber o Espaço Cênico muito mais teatral, mais além do que quer dizer "aqui agora."

O $1^{\circ}$ Teat(r)o Oficina, foi criado pelo Arquiteto Joaquim Guedes com duas Platéias confrontadas; no Teatro em que nós, Atuadores, éramos a Carne do Sanduiche. Este Teatro atingiu o apogeu com a montagem de "Pequenos Burgueses" de Gorki, recriado para a situação pré-revolucionária brasileira, nossa e de nosso público. Tivemos mais de 1.000 apresentações, até o Golpe Militar de 1964. Os Teatros todos de SamPã foram fechados e reabertos pela estratégia brilhante das duas divas Cacilda Becker e Maria della Costa que conduziu toda a classe Teatral da cidade à Masmorra Sórdida do DOPS (Prisão política, onde estava presa a grande atriz Cleyde Yaconis). Foram vestidas na maior elegância possível, chegando ao lugar num cortejo de carros do ano, sob as luzes da TV e conquistaram para a Cidade o Retorno do Grandioso Teatro Paulista de então.

Nesta fase encontramos BRECHT e trabalhamos "ANDORRA" de Max Frish, com o Método do Teatro Épico, peça que penetrava no terror da época: CAÇA AOS BODES COMUNISTAS, que justificava o Golpe Militar com ligação com o Pentágono. Mas, a Ditadura Militar cresceu e dilacerou o Bairro através de um Viaduto monstruoso que o dividiu em dois. 


\section{O TEATRO OFICINA FOI INCENDIADO POR GRUPOS DE PARAMILITARES}

O Teatro Oficina, foi reconstruído pelo Artista, Cenógrafo, Arquiteto Flavio Império, a meu pedido, muito influenciado por Brecht. Mas a sua Inauguração em 1967 trouxe à tona, "O REI DA VELA" do Grande Poeta Brasileiro OSWALD DE ANDRADE e entramos na revolução Cultural de Descolonização completa do Brasil do Hemisfério Norte, Retomando a Antropofagia da Cultura dos Índios Caetés que comeram o Bispo Português Sardinha que ia à Europa buscar mulheres brancas, para cruzarem com os colonos Portugueses. Com esta montagem devoramos o Teatro do Hemisfério Norte, comidos pelas culturas que assumimos em nosso corpo: a dos índios, dos escravos africanos, dos emigrantes que cozinharam a massa da mestiçagem dos Baixos do Brasil.

OSWALD foi a grande Antena que em 1967 religou a previsão da "TERRA EM TRANSE" do que viria em 1968 no Mundo de GLAUBER ROCHA, "A TROPICáLIA" de Helio Oiticica que tirou o Quadro da Parede e vestiu-o como "PARANGOLÉ "e criou a AMBIÊNCIA PLÁSTICA DE UM ESPAÇO CORPO NUMA OBRA CHAMADA "TROPICÁLIA" Esta obra daria o nome ao Movimento "TROPICÁLIA", musicado por CAETANO VELOSO e GILBERTO GIL. OSWALD DE ANDRADE vinha da "SEMANA DE ARTE MODERNA" de 1922, mas em 1928, declarou: "Sou 1 Pós-Moderno do Mundo e criou o "MANIFESTO ANTROPÓFAGO".

A Seguir, no fim de 1967, "RODA VIVA" de CHICO BUARQUE DE HOLLANDA, dirigido por mim, buscava num teste, um Corinho de 4 atores para o Musical, num Teatrinho do Rio de Janeiro em que os funcionários vestiam-se como os escravos do Brasil Colônia, nos figurinos dos quadros de Debret. Fomos ocupados, tomados comidos, por uma geração de dezenas de jovens atores pagãos que surgiram Telúricos num Coro Arcaico, vindo dos Ditirambos da Grécia e comandaram o Rito como Coros Gregos Ctônicos Gregos-Negros-Mestiços. Este Coro completou a revolução de "O REI DA VELA" tanto que, para mim, as duas peças, são a mesma peça. Grupos Paramilitares assistiram 70 vezes o grande sucesso que era a peça, numa chamada "Operação Quadrado Morto" para, no fim de um dos espetáculos, Invadir o Teatro, destruir os Equipamentos, Poltronas, sobretudo bater nos Artistas que faziam a peça. O espetáculo continuou em Cartaz com um Apoio Alucinado do Público de 1968 (este foi um ano muito poderoso para o Teatro), mas, quando apresentado em Porto Alegre, o próprio Exército Brasileiro cercou o hotel onde estavam os Atores, perseguiu-os espancando-os, sequestrando uma Atriz e um Violonista pro meio do Mato, torturando- 
-os com ameaça de Estupro. Tortura Coletiva. Cortaram os telefones do Hotel, meteram todos os atuadores sangrando num Ônibus de volta pra São Paulo. Era o Ato nํㅗ, o Al-5 chegando, o maior torturador e repressivo da Ditadura,

No dia de sua Instituição, dia 13 de dezembro de 1968, estreávamos "GALILEU GALILEI" no Teat(r)o Oficina, atrás de uma grade, em que o Coro de "Roda Viva" que contracenava fisicamente com o público, foi proibido até de, simplesmente, olhar para a Platéia. Criamos um dos nossos mais belos espetáculos "A SELVA DAS CIDADES" do Jovem Brecht. Enquanto a Ditadura Militar rasgava o BIXIGA em dois, como o Muro de Berlin, com a Construção de um Viaduto q levava o nome do General Ditador. O povo apelidou de MINHOCÃO e o nome pegou.

Mas, a Especulação invadiu o Bairro destruindo-o completamente. Chegamos a encenar um Trabalho Novo, clandestinamente, durante uma Viagem batizada de "UTROPIA" pelo Brasil todo: apresentando, nos Belos Teatros Oficinais de Palco Italiano das Capitais do Brasil, nossos sucessos, para pagarmos nossas investidas secretas pelo Sertão. Criamos na Língua do Silêncio o chamado "Lição de Voltar a Querer: RE-VOLIÇÃO” ou "GRACIAS SEÑOR'. Atuávamos com os sertanejos, em silêncio, realizando Obras como Antonio Conselheiro nos Sertões, construindo Pontes, reavivando solidariedade nas cidades em casas que trabalhavam tecidos para vender à Capital SamPã...

Estes Teatos foram o embrião da montagem das 77 horas, em 5 peças de "OS SERTÕES”, de Euclides da Cunha. Obra reveladora dos dois Brasis, o do litoral colonizado e o do País de Dentro, ainda indomado . O livro mais traduzido do Brasil. Estreamos no Rio e depois da Viagem a pesquisa aprofundou-se e retornamos a São Paulo com um espetáculo em dois dias, quase mudo chamado "Gracias Senõr". 40 Censores de São Paulo exigiram da Polícia Federal que retirasse de cartaz este Rito Silencioso. Éramos acusados de termos sido "ensinados pelos chineses com técnicas de hipnotização das Massas". Mas, a Polícia Federal estava interessada em estudar nossos Métodos e custou a ceder à Censura da Polícia de São Paulo. Finalmente a Polícia Federal proibiu o Rito e transformamos o Teatro numa "Assembléia Permanente de ROCK", com grupos que roqueiros que nasciam na cidade.

A Ditadura foi evoluindo na série de torturas, assassinatos, até instituir um Regime de Explícito Terror. Fomos nos cercando, nós começamos a morar dentro do Teatro e nos associando a artistas de outras áreas, principalmente da Imprensa Revolucionária 
da Época, chamada Nanica, que fazia o Jornal "BONDINHO" censurado, reaparecido com o nome de "EX". Nesta fase o Teatro foi invadido pela Polícia, os que la estavam foram presos, mas a polícia que atirou no Beco do fundo teve as balas devolvidas nos braços do Atirador. Saíram manchetes nos Jornais e TVs: Oficina resiste à bala, a Polícia.

Foi a fase que fomos presos, Torturados, e Exilados. Parte do Grupo Oficina, saiu do Brasil clandestinamente e parte foi exilada. Encontramo-nos na revolução Portuguesa dos Cravos onde Vivemos uma Comunidade Internacional chamada "OFICINA SAMBA" Com a repressão da Revolução dos Cravos, dia 25 de novembro de 1975 via TV, por uma emissão vinda do Porto na RTP de Lisboa, fomos testemunhas do $1^{\circ}$ Golpe Militar via TV. A TV de Lisboa teve de fechar a janela aberta totalmente ao povo, como um telefone coletivo público e entrou no Monitor do restaurante, a Imagem da Columbia Pictures anunciando "The Man who Comes to Dinner", e na sequência de semanas de enlatados brasileiros e americanos. Uma parte do Grupo foi para Moçambique onde havíamos filmado a festa da Independência com apoio da FRELIMO, num documentário não- linear, musical chamado "25".

Fomos montar em Londres e em Paris patrocinados pelo Ministério da Comunicação de Moçambique, porque os Colonos Portugueses Retornados tomaram a televisão e queriam queimar o filme. Lançamos o filme na TV Francesa e veio a "abertura, longa, restrita e progressiva" no Brasil que durou toda década de 80 . Cacilda Becker a grande líder "Antígone Chanel" de 68, faleceu em 1969, depois de um Coma de 40 dias que se iniciou no intervalo de "ESPERANDO GODOT," em que ela fazia Estragon. O Teatro Brasileiro foi entrando em COMA. Os melhores artistas de Teatro foram comprados pela TV. O Teatro recuou. No Nosso retorno passamos a seguir em direção contrária ao "main stream," modernizado com o palco italiano transformado em vitrine Dark.

Hoje o pequeno espaço do Teatro em SamPã, pertence à miséria dos Monólogos, aos Stand Ups, e ao Teatro de Costumes para Auto Ajuda à Burguesia Velha. Os jovens de 68 arregaram e viraram velhos decrépitos e ricos.

Reocupamos o Teat(r)o Oficina que ficou sob a guarda de um grande artista, Luiz Antonio Martinez Corrêa, meu irmão, que criou com muito sucesso sua Cia. PÃO E CIRCO. Mudou-se para o Rio e passou a guarda do Teatro à Bilheteira do Oficina dos anos 60: TEREZA BASTOS. Na nossa volta, como tínhamos passado pela Revolução Portuguesa e Moçambicana, achávamos que a situação do Brasil era a mesma, e começamos a nos desfazer do palco Italiano, para realizar o Projeto do Terreiro Eletrô- 
nico, do Teatro Pé na Estrada, Rua de Passagem para o Teatro de Estádio trabalhando com o "Arquiteto" Lina Bardi, abrindo o espaço para os Nordestinos, os Negros do Bixiga, abrindo uma Cozinha Cabaret com a fantástica Cozinheira ALAGOANA ZURIA.

O grande músico pernambucano EDGARD FERREIRA, sua mulher SANDY CELESTE, uma Billie Holiday Sertaneja, SURUBIM FELICIANO DA PAIXAO, um Cirandeiro e Pintor que sexualizou a arte folclórica popular do Mestre Vitalino de Pernambuco. Fundamos o "FORRÓ DO AVANÇO" totalmente aberto à Cidade e ao Bairro do Bexiga. Este Forró Misturava uma nova Geração do Circo e nele foi criada uma nova engenharia para o Teat(r)o Oficina. Catherine Hirsh Poeta Francês, criou os estatutos da ASSOCIAÇÃO DE TRABALHOS DE COMUNICAÇÃO SEM FRONTEIRAS, TEAT(R)O OFICINA UZYNA UZONA COM os seguintes Núcleos:

1- "OS SERTÕES"- sobretudo com os Sertanejos, nortistas e negros de SAMPÃ, em torno da Obra homônima de Euclides da Cunha.

2- "AS BACANTES"- com jovens vindos do Brasil todo, reconstituindo o rito de Origem do Teat(r)o.

3- "O HOMEM E O CAVALO"- com os jovens montados nos Cavalos Tecnológicos das Câmeras, Projetores, enfim, o Cinema e o Vídeo que começava a aparecer como um instrumento de grande valia nas conquistas políticas.

Seguimos os exemplos dos Índios, invadindo os campos oficiais em Círculo e com a Enorme Câmera de Vídeo Umatic; um Cavalo de Tróia a altura do momento de Abrir Brechas na Abertura Fechada. Foram anos subterrâneos em que trabalhamos as maquetes vivas, das futuras peças que fizemos, quando voltamos à tona com o Terreiro Eletrônico Pronto.

Trabalhávamos com estas obras por 13 anos, ao mesmo tempo em que com ações de TE-ATOS levantávamos os meios físicos de ir construindo o Terreiro que queríamos. São anos que estão muito bem captados no livro "UMA PULSÃO ESPETACULAR", do Psicanalista Lacaniano MAURO MEICHES². O Foco do trabalho se inicia, principalmente, na Religião Dionisíaca e na Origem do Rito Teatral que Eurípedes documentou em sua última peça "BACANTES". A Obra foi recriada na língua poética brazyleira, dos Grandes Poetas como Vinícius de Morais que, com "Orfeu do Carnaval" estabeleceu a ligação entre o "CANDOMBLÉ AFRICANO e a MITOLOGIA GREGA. Com as letras das músicas mais populares da era de Ouro do Samba, dos Pontos dos

${ }^{2}$ Meiches, Mauro. Uma pulsão espetacular: psicanálise e teatro. Escuta/FAPESP, SP, 1997 
Terreiros de Macumba, até chegarmos à "ÓPERA DE CARNAVAL ELEKTROKANDOMBLAICA", à "TRAGYCOMÉDIORGYA",

Atualmente, ao mesmo tempo em que Programamos O "TEATRO DE ESTÁDIO OSWALD DE ANDRADE", e a "UNIVERSIDADE ANTROPÓFAGA" vinda do "BEXIGÃO: "Teat(r)o com a criação do Bairro Periférico do Centro de São Paulo, (pra nós: SAMPÃ), o BAIRRO do BIXIGA, onde há 54 anos o TEAT(r)O OFICINA está incrustado. Evoluímos para a criação de uma "CRECHE que tem o nome de uma das cenas de 'O HOMEM E O CAVALO" de Oswald de Andrade: "A VERDADE NA BOCA DAS CRIANÇAS", assim como, "A OFICINA DE FLORESTAS" que desde já, refloresta dentro e fora o TEAT(r)O OFICINA UZYNA UZONA, espreguiçando-se em todo seu entorno, até os limites do BIXIGA.

Depois de 30 anos lutando com o Grupo VÍDEO-FINANCEIRO SS, da SBT, dirigida pelo Gigante de Mídia, SÍLVIO SANTOS. O Artista Comunicador Silvio Santos, depois de 30 anos de Luta com OFICINA, fez sair de Cartaz esta peça, emprestando-nos os Terrenos que nos circundam, totalmente destruído, para Obras de Torres e de Um SHOPPING CENTER que o Grupo queria construir no entorno do Teatro. Ao mesmo tempo, hoje, Sílvio Santos propõe a troca de seus terrenos com a Federação, Estado ou Prefeitura de São Paulo, para que possamos construir o Projeto que hoje chamamos, mais uma vez, em referência à Obra Ciclópica, Homérica, proposta por OSWALD DE ANDRADE: de ESTRATOPORTO.

Lutamos por uma Política de tornar nossa Rua de Passagem como é nosso Teatro no Bixiga, dando para uma Apoteose num Teatro de, pelo menos, 5.000 lugares. Acreditamos no Grande Público que pagará ingressos mais baratos e na Produção Virtual de DVDs absolutamente profissionais sobre nossos trabalhos, que já estão no Mercado.

Queremos no Teatro de Estádio realizar em 2014 uma COPA de TEAT(r)O com gente do mundo inteiro playing, jogando no Estádio. Os investimentos no Brasil para Festivais de Teatro com o Brasil no BRICS irão crescer na medida em que conseguirmos construir um Teatro Visível no Centro de Sampa. Vejo o Teatro de Estádio, nesta época de auditórios em Shoppings, ou cubículos dos chamados grupos de Vanguarda, trazendo a EPIFANIA URBANA DESTA ARTE CIÊNCIA. Os Teatros do Mundo na Era dos BRICS devem, - pelo menos na China, na Índia, na África, na America Indo-Negra-Latina, - abrirem-se à riqueza de seus povos, misturando-os, proporcionando semanas de convívio Olímpico. 
O Teatro precisa ser algo VISÍVEL, pois desapareceu da percepção da multidão. A Europa, os EEUU nesta crise estão muito fechados em si mesmos, mas se quiserem participar do Renascimento que já existe latente no mundo terão de se abrir para esta nova Riqueza da era da Economia Verde: a Arte de uma Humanidade Poderosa, que através do Teatro busca agora a não-extinção da Espécie Humana, hoje um REBANHO.

As espécies todas preservadas irão no Teatro Amasiado ao Circo, contracenar com os bichos, plantas que não se extinguirão e principalmente com o neguinho, o homem como chamam, preservado, expandido, saído da condição de rebanho em extinção dos dias de hoje.

\section{Como é o processo de criação do grupo?}

Foi transformando-se, nos 53 anos de vida do Oficina, que se pode dividir em duas grandes fases:

1- A Inicial - nos processos recriados do Método Stanislávski, depois de Brecht, Artaud, Grotowiski. Uma fase de devoração do Teatro Ocidental do Hemisfério Norte, com montagens de peças do Hemisfério Norte e do Sul.

2- A partir da encenação de "O REI DA VELA," de Oswald de Andrade, quando descobrimos o TEATRO ANTROPÓFAGO, invertendo os valores da Colonização do Hemisfério Norte, retornando ao Teatro dos Ritos Arcaicos da Antropofagia Indígena, do Candomblé inventado pelos Escravos Africanos, da Música Popular Brasileira, do Samba, do DYTIRAMBO DIONISÍACO, a inversão dos TABUS OCIDENTAIS JUDAICO- CRISTÃOS PARA OS TOTENS DOS POVOS ARCAICOS E CONTEMPORÂNEOS BÁRBAROS TECNIZADOS.

Ligamo-nos aos Processos das Escolas de Samba de Carnaval, aos rituais de iniciação do descabaçamento do Corpo Ocidental, para um Teatro Rebolado, que assumiu desde o Rito Religioso ao Profano do Teatro de Revista, ao Circo, mas Tecnizados, pelo Cinema, TV, e agora com a Revolução da Internet. É um método inspirado no "aqui agora" de cada instante, criando as peças do repertório como Obras Abertas, em permanente transformação e atualização. O Teato é filho do tempo e do ser sendo.

O Trabalho de atuação diretamente inspirado no Auto Coroamento Dionisíaco, passando pelo Malho da Bigorna, transfigurando-se como "Pentheu" na peça que, depois do Estraçalhamento, se transmuta em Apolo.

Os Atuadores de todas as Áreas, os que criam as Entidades, os Coros das peças e os Técnicos Bárbaros Tecnizados, Arquitetos do Espaço Cênico, Criadores dos Para- 
mentos Rituais, Iluminadores de Luz e de Imagens de Vivo ao vivo, transmitido em Direto, ao mesmo tempo em que, contracenando com Imagens Virtuais, os Quadros Atuais, Câmeras, Cortadores, Camareiras, Contra Regras, Dançarinos-Contra regras, que chamamos de IONs, guardadores do Terreiro. Este conjunto trabalha os Roteiros e levanta a peça juntamente, precedido de um trabalho Corporal, Vocal que coloque todos na Mania da CONCENTRAÇÃO DA ENERGIA OCUPANDO TODO ESPAÇO DO TEAT(r)O EM QUE ATUA E SEUS ARREDORES.

O Processo de Criação leva à MAGNETIZACÃO DO ESPAÇO CÊNICO, com a mistura de todas as Mídias, da Corporal, às máquinas de um grande Corpo Sem Órgãos, que através do Teto Móvel do Teatro, entra em contato com o Universo Urbano e Cósmico .

Desde o início, foi um trabalho profundamente individualista e coletivo, coletivo-afetivo, não éramos sérios, como os coletivos marxistas ou os Teatros Profissionais das peças de Costumes. Juridicamente, no início, éramos uma Sociedade Ltda, mas sempre atuamos de maneira auto-organizada, com todo elenco criando as peças e envolvido na Produção. Era muito fácil esta Época, criamos um Teatro em 8 meses. Os ventos sopravam a nosso favor. Trabalhavamos esta $1^{\text {a }}$ fase a quebra emocional dos Clichês que nos levavam á "representação" para nos suicidarmos como "PEQUENOS BURGUESES" e ressuscitarmos Corpos Emocionados, ao vivo no aqui agora, atuando com o sentimento do Público presente, mas sem ainda nos dirigirmos diretamente a ele, mas sintonizando-nos interiormente com suas energias.

Éramos colonizados ainda, mas já devoradores de Stanislávski, que já nos aproximávamos da Macumba Africana e, mais precisamente, da onda pré-revolucionária que crescia no Brasil.

Depois de Golpeados Militarmente em 1964, descobrimos Oswald de Andrade que é trazido à cena com a inauguração do novo OFICINA, depois do 1ำ queimado, construído o $2^{\circ}$ em 1 ano e meio.

Oswald tinha vivido a Arte Pública Soviética do início da Revolução Russa, já tinha comido Mayerhold, Maiakoviski, a vanguarda francesa. Sua peça encenada quebrava todos os cânones realistas, criando um $1^{\circ}$ Ato Cubista, um $2^{\circ}$ Ato, trazendo o retorno do Velho e Maravilhoso Teatro de Revista, a Chanchada do Cinema Brasileiro, e o 3º, a Ópera Vagabunda dos Circos finalizando com uma Missa Negra. Fui somente o diretor, e os atores traziam as Máscaras das Entidades, nos Figurinos, Maquillagens e direção 
de Arte do fabuloso Helio EichBauer, vindo de Praga, do estudo com SVOBODA. As Entidades atuavam como na Umbanda e no Candomblé:

-Abelardo I "O Rei da Vela", O Banqueiro em sua Vida, Paixão e morte, sucedido por seu Secretário.

-Abelardo II, o $1^{\text {o }}$ Socialista do Teatro Brasileiro, na disputa do Poder da Especulação e das Terras da Aristocracia Decadente do Café, incorporada primeiro;

-em Heloisa de Lesbos, de uma FamILHA da Aristocracia rural que tentava se salvar unindo-se aos "nouveau riche: os especuladores;

-Dona Cesarina, uma Madame Burguesa;

-O filho Gay Totó Fruta do Conde, inspirado pela estada de Nijinski no Brasil, vestido de Odalisca;

-Perdigoto, o Fascista de Farda Verde;

- João dos Divãs- Menina Lésbica de bigodes, luvas de Box, vestida de Shirley Temple;

-a Velha Dona Poloca, representando a Tradição na defesa da Pátria, da Família, da Propriedade e de Deus;

-O Povo Enjaulado nas mãos dos agiotas;

-e o General Americano, Mr. Jones, encarnando o Rei dos Reis o "Good Business".

Toda esta fauna de ENTIDADES está no Filme da Peça, proibido na Ditadura, mas hoje sendo remasterizada. Macumba TragiCômicaOrgyastíca do Poder no Brasil. Esta peça, depois do Coro Tectônico que surgiu no "Roda Viva", trouxe a "Ópera de Carnaval."

A Repressão Violenta no fim de 1968, tornou impraticável a prática do Teatro Antropófago, mas antes fizemos o Trabalho Mudo de Te-Ato, já mencionado anteriormente e a versão Cogumelo das "Tres Irmãs" de Tchecov. Na fase pós-retorno do Exílio, encenamos "As Boas" de Jean Genet, com a estreia do que hoje, 25 anos depois, revelaria o $1^{\circ}$ Ator do Oficina: o Ator-Rei Marcelo Drummond fazendo Clara, eu fazendo Solange, e Raul Cortez, um dos atores mais fortes do Brasil, celebridade de Cinema, Teatro e TV, nos anos 60/80/90, que já havia se notabilizado pelo seu trabalho em "Pequenos Burgueses"-fazendo a MADAME. Raul endossou a possibilidade de emergirmos dos anos de clandestinos na abertura da Ditadura Brasileira.

Reconstruído o Espaço do Oficina como "Terreiro Eletrônico" abre-se o novo Teatro, o 3ํㅡㄹ com "Ham-let, "(Solta-o-Canastrão) trabalhado já com Coros e as protagonizações de Entidades reunidas, tendo um Ham-let Solar na atuação de Marcelo 
Drummond, o próprio Ham-let, que junta os atores de sua geração na montagem do texto integral de Shakespeare, devorado em seu poema infindo: Hamlet por Marcelo-Ham-Let, o Crítico Teatral da "Folha de São Paulo "Nelso de Sá e eu, que retornava ao Oficina, na Entidade do Fantasma Rei Ham-Let que passa o Bastão do Teat(r)o à Ham-let Marcelo Drummond.

A partir de Oswald de Andrade e da obra de Nietzsche que reconstruiu todo sub-texto de Dionísios em suas obras, devoramos em encenações Antropófagas tendendo cada vez mais para um Teatro Música, Dança e Bruxaria. A Pista-Rua do novo Teat(r)o Oficina desemboca agora no Terreno de seu Entorno, de todo um quarteirão.

Depois de "Ham-let" trabalhamos nos "MISTÉRIOS DE ELEUSYS" criado por Oswald de Andrade, uma peça chamada "Santeiro do Mangue" ou "MISTÉRIOS GOZOZOS EM FORMA DE ÓPERA” Um mistério religioso poético que Oswald escreveu inspirado nas Putas do Mangue do Rio de Janeiro, em sua linguagem, em seus ritmos com o Corcovado como Personagem que, no final, é comprado por um Ex-Vendedor de Santos que se torna Cafetão da Puta EDULÉIA. Eduleia recebe o presente do Santo, despe-o de sua roupagem, que abençoa dos Morros, o Rio de Janeiro, e quando o vê nu, vê revelado o Mistério e proclama extasiada de joelhos: "É O CARAIO"!

Esta peça nos deu a chave para a Criação de "BACANTES" que estudamos 13 anos, e recriamos como Rito da Origem do Teatro, como índios que descobrem o esquecido Mito Original de sua Tribo. Com COROS de Bacãs e Satyros, e protagonistas Deuses e Mortais retornamos ao Teatro ctônico. Criamos "BOCA DE OURO", uma das muitas Obras Primas de Nelson Rodrigues, também em forma de um Ritual Azteca.

"Os Sertões" de Euclides da Cunha é nossa maior Obra. Foram seis anos de criação de cada parte do livro, em 5 peças: "A TERRA"; "O HOMEM I"(do Pré-homem ao Homem); "O HOMEM II" (do Homem ao Trans-Homem); "A LUTA I"; "A LUTA II". Esta Obra foi apresentada por todo o Brasil em Tendas para 1.000 pessoas, e culminou no Sertão de Quixeramobim, onde nasceu Antonio Conselheiro o Profeta da Guerra de Canudos, a $1^{\text {a }}$ Guerra transmitida Mundialmente por Telégrafo e depois foi apresentada em CANUDOS, a cidade de 25.000 pessoas, construída pelos Sertanejos no fim do Século XIX, Sociedade auto-organizada. Esta cidade despertou a ira dos Militares Republicanos e da Igreja Católica. A República declarou Guerra a Canudos e o Exército Brasileiro foi derrotado 3 vezes, até que uma 4⿳亠丷厂 Expedição massacrou Canudos. Esta peça foi para a Alemanha no Festival de Reckling Hause e depois em 
2005 em Berlim no Volksbhune, considerado o evento mais importante deste ano, pela Midia Berlinense. O processo misturou as crianças do Bixigão com os adultos, e em cada cidade que nos apresentávamos, trabalhávamos uma cena com as crianças do local. Elas enriqueceram os ritmos da peça: as crianças cariocas, trazendo no corpo o Funk Carioca; as Baianas, o Axé; as Pernambucanas, o Frevo e o Beat Mangue. Este trabalho era atuado com todo o público presente nos espaços.

Talvez o mais importante no nosso Processo atual de Trabalho, seja a dádiva do espetáculo como se canta no $1^{\circ}$ Canto de BACANTES:

Pra si,

pra mim

pro sol

Atuamos com o Público,

Aprendemos com o Carnaval

Com os terreiros de Macumba e Umbanda,

O contato de Amante,

Nós, em cena, e o Amado Público,

Para criarmos os Ritos de cada Dia ou Noite.

Há a exigência extrema aos atores, para que destruam a representação do THEATRO e cheguem à presentação do TEATO.

Mas, misturamos os dois no TEAT(r)O aprendendo a lidar conosco mesmos (pra mim) com o público: Olimpo de Dionísios (pra si)

com o Cosmos (pro Sol)

É um treino que passa pelas danças e rituais religiosos de bruxaria Africana, Indígena, Yoga e Tai Chi Chuan - rebolados para os 4 cantos do Universo, mais o Céu e o Inferno, que temos materializado no Oficina, no Teto Aberto para o Espaço Celeste e nos subterrâneos que foram construídos durante "Os Sertões".

Escrevi uma TETRALOGIA: CACILDAS!, !!, !!!, em torno da Atriz Elétrica de presença absolutamente magnética que foi a Grande Artista criadora do Teatro Brasileiro que nos antecedeu. Além de grande Atriz, Cacilda deixou cartas sobre seu método misterioso de atuação. Nestas peças procuro, em sua encenação, trazer a história prática do Teatro Brasileiro antes de nós e a Luta pelo ATOR ATRIZ DE CORPO ELÉTRICO. Cacilda Becker realizou o que Artaud escreveu e performou. Já fizemos a $1^{\text {a }}$ Exclamação Cacilda! e a $2^{\text {a }}$ Cacilda !! Em breve vamos fazer Cacilda !! que é a que 
criou no TBC a Maior Cia. de Teatro Moderno Brasileiro nos anos 40 e 50. No nosso processo adoramos introjetar o Passado do Teatro, do Circo, do Teatro de Revista Rebolado e dos Ritos Indígenas e Africanos, além de outros.

Tivemos a experiência de trabalhar o CORPO SEM ÓRGÃOS encenando a transmissão radiofônica de Artaud "PRA DAR UM FIM AO JUÍZO DE DEUS".

"O BANQUETE” de Platão foi recriado num Banquete com muito vinho, e com a desmistificação do Amor Platônico, assim interpretado pelos Monges da Idade Média. Banqueteávamos com o Público, trazendo o Amor Platônico como a FODA DOS ESTETAS. Ao Amor procriador de filhos carnais e de filhos de Poetas em suas Fodas criadoras de Obras Vivas, mais eternas que os Filhos Carnais.

Atualmente, criamos a encenação do "MANIFESTO ANTROPÓFAGO", de Oswald de Andrade. "MACUMBA URBANA ANTROPÓFAGA" parte nas Ruas do BIXIGA, com paradas no apartamento onde morou Oswald de Andrade, onde vamos chamá-lo para beber o leite de uma Cabra. Ele desce de Pijama e tira o leite da Cabra e comunga com o Bicho totem do Teatro Dionisíaco e daqui do Trópico das Cabras.

\section{Qual é o lugar da dramaturgia na cena?}

Não acredito em Drama, já BACANTES termina assim :

“E assim acaba o Drama

Pã Pã Pã Pã

E a Dramaturgia

Pã Pã Pã

E assim começa...

A TragyKomédiOrgya

Não porque não suporto mais "play right", nem Drama. Adoro as mil línguas de todas as linguagens que phalam a vida e seus instrumentos. É na presença viva de cada público, seja na Rua ou nos Teatros, que as cenas existem com seus Múltiplos Sentidos, numa Babel que traz a energia criadora poderosa de cada dia-noite-madrugada.

Os Europeus agora inventaram um teatro fechado em si mesmo, como o "Europa da Economia", de Angela Merkel. Estão com muitos milhões de Euros para produzir peças com atores dos Países Europeus, em diferentes línguas. Mas, essas culturas estão mortas, a Globalização trouxe a Globalização do Teatro que se faz na percepção do Renascimento do Globo na Economia Verde. 
Vejo o nosso trabalho como algo totalmente fora dos mainstreams, caminhando em direção inversa aos Monólogos, Stand Ups, Dramas, Palco Italiano, Teatro da Incomunicabilidade Humana, Vanguarda etc.... Caminhamos no Oficina Uzyna Uzona, na retomada do Poder do Teatro Primitivo Ritual com as Multidões nas Práticas de seus Rituais como Carnaval, Cyrio de Nazaré, Teatro Grego, no Poder das Entidades Shakespearianas, das Entidades do Nô Japonês, do Teatro de Revista, enfim, vamos comendo toda história do teatro, na contemporaneidade da Internet e das Porcarias da TV. Na saída da Idade Mydia. No Retorno à condição universal de bicho humano, de Índio. Não sei porque, agora detesto a palavra "Homem," "Mulher"... Caetano Veloso inventou uma palavra interessante para os seres que compõem a humanidade: "Neguinho"' Globalizados somente enquanto Neguinhos Tecnizados da criação de todos os neguinhos aqui agora, no passado, futuro e presente vivos em nossos DNAS.

\section{Qual o papel do espectador no seu trabalho hoje?}

Não é uma questão é uma resposta. Tupy or not Tupy? Não. Tupy é a resposta: ser no Rito. O espectador ou é ator mesmo mudo, sentado, isto é, e assim entra na Mágica Teatral ou não vê, não entende nada. Einstein já sabia que somos sujeitos do objeto com que lidamos, e ao mesmo tempo objetos. Estamos todos dentro. Somente fazendo, descobrimos e vemos: nos fazemos juntos. Não há uma terceira pessoa. Somos todos Atores do Teat(r)o em que damos a energia de nossa presença viva. Não há Arte, Ciência, Mágica sem se estar por dentro dela. Queremos a humanidade Bárbara, tecnizada, renascida irreverente, demasiadamente humana, trans-humana, poderosa. 